\title{
Febre a bordo: migrantes, epidemias, quarentenas
}

Fever aboard: migrants, epidemics, quarantines

Cristiana Bastos ${ }^{\star}$

*Universidade de Lisboa - Lisboa, Portugal

(Investigadora Principal, ERC-2015-AdG 695573)

cristiana.bastos@ics.ulisboa.pt

https://orcid.org/0000-0001-5387-4770 


\title{
Resumo
}

Neste artigo faço uma retrospetiva dos estudos sobre epidemias a que me dediquei enquanto antropóloga, dando destaque a um fenómeno que interseta os interesses da antropologia da biossegurança e da história das plantações de açúcar e migrações laborais: os surtos epidémicos a bordo dos barcos de migrantes em finais do século XIX. Baseada num relato de mais de 50 mortes infantis por sarampo numa viagem de emigrantes da Madeira para o Hawaii em 1884, e constatando que existiu uma sequência de pelo menos três mortandades equivalentes no espaço de dois anos, discuto questões mais amplas de saúde, desigualdade, tráfico, corpo, género, família, não sem dar atenção à materialidade da vida dos navios que se foram reconfigurando no transporte de força do trabalho escravizada, vinculada e contratada.

Palavras-chave: epidemias; migrantes; Hawaii; Guiana.

\begin{abstract}
In this article I present an overview of my previous work on epidemics, leading to a new topic that stands at the intersection of an anthropology of biosecurity and a critical history of sugar plantation societies: the epidemics on board of late $19^{\text {th }}$ century migrant ships. Starting with a report about a measles outburst on a steamer carrying migrants from Madeira to Hawaii in 1884, in which over fifty children died of the disease, and realizing that this was one of a sequence of at least three equivalent devastations in less than two years, I discuss broader questions of health, social inequalities, trade in humans, body, gender, kinship, not without a focus on the materiality of the vessels that transported the labor force, whether in enslavement, indenture, sponsored contracts or other modalities of bondage.
\end{abstract}

Keywords: epidemics; migrants; Hawaii; Guyana. 


\section{Retrospetiva: antropologia e epidemias ${ }^{1}$}

Enquanto antropóloga trabalhei com diferentes epidemias e usei vários ângulos disciplinares - da antropologia médica, sobretudo na sua vertente dedicada ao conhecimento biomédico, mas também no estudo da confluência de práticas e conhecimentos de matrizes múltiplas; da saúde pública, incluindo a vertente de políticas públicas; do estudo social da ciência e tecnologia; da história da ciência, tecnologia e medicina; da história social da medicina; da sociologia do conhecimento; e, em alguns momentos cognitivamente privilegiados, interagi com grupos especializados no estudo social das epidemias, desde as bíblicas pestes e lepra ao futurista "apocalipse zombie", que extravasou do vocabulário do cinema e videojogos para o da saúde pública enquanto código para emergências e epidemias imprevistas. ${ }^{2}$

Foi recorrendo a essas perspetivas múltiplas que estudei doenças infecciosas epidémicas e em alguns casos endémicas, desde a AIDS à sífilis, incluindo a varíola, peste, cólera, malária, e, mais recentemente, o sarampo infantil e outras moléstias que com frequência grassaram nos barcos de emigrantes.

Este último interesse insere-se num quadro mais amplo de estudo do corpo em mobilidade, não apenas na expressão de doenças, mas também nos termos da sua utilização no trabalho forçado extremo, sobretudo na plantation - latifúndio, herdade, fazenda, ou, simplesmente, plantação. Desse contexto e problemas realço hoje a materialidade e experiência humana envolvida na importação de força de trabalho que se traduzia em longas viagens marítimas entre o lugar de origem e a plantação do destino. Tal como aponta Sowande' Mustakeem (2016) para os navios escravistas, já a bordo se jogavam as

1 Este artigo foi originalmente apresentado no simpósio "Mapeando controvérsias contemporâneas: ecologia, saúde, biossegurança”, Porto Alegre, UFRGS, 12/07/2018. Agradeço a Jean Segata o convite e apoio, e aos demais colegas presentes agradeço a estimulante discussão. O estudo das epidemias a bordo foi feito no âmbito do projeto "The colour of labour - the racialized lives of migrants", que coordeno com o apoio do European Research Council (ERC-2015-Advanced Grant 695573). Agradeço ao ERC o generoso apoio; ao Instituto de Ciências Sociais da Universidade de Lisboa, minha instituição, a liberdade de investigação; aos membros da equipa, a interlocução; aos inúmeros bibliotecários e arquivistas que partilharam momentos desta jornada, com escalas no Funchal, Honolulu, Manoa, Greenwhich, Kew, Londres e Lisboa, o generoso acolhimento.

2 Esta dimensão da vigilância sanitária foi-me apresentada por Maximilian Mehler no encontro "Epidemic entanglements", organizado por Meike Wolf e Kevin Hall na Goethe-Universität em Frankfurt (ver Madsen, 2014). 
condições de punição, dependência e sofrimento que formatavam aqueles que iam constituir a mais desumanizada força de trabalho, a dos africanos escravizados nas plantações das Américas e Caribe. Embora em outras condições, também a viagem de emigrantes tinha na passagem marítima uma componente de experiência radical que poucas vezes é tomada em conta nos estudos das sociedades e economias de plantação. Nessas longas viagens irrompiam epidemias, estados febris, alienação, ruturas, devastação, morte, luto. Mas antes de chegar às febres a bordo e às grandes viagens em que ocorriam, apresentarei a sequência de pesquisas e os nexos epidémico-interpretativos que me levaram a pontos cada vez mais distantes, culminando no porto de Honolulu.

\section{AIDS e contemporaneidade: conexões globais}

A AIDS foi primeira epidemia que acompanhei, ainda na pós-graduação, e durante a viragem para a década de 1990 (Bastos, 1999, 2002). A pesquisa ocorreu no Brasil, nos Estados Unidos e em organizações mundiais; foi antes de estar instalada a internet como modo de comunicação, instrumento de investigação, e universo com agência própria, mas as conexões globais já existiam, e alguns de nós tentaram abordá-las, dimensionando a pesquisa para vários lugares em simultâneo, seguindo fluxos de comunicação e transformação de práticas e cognições (Bastos, 2010; Hannerz, 1996).

Foi assim que acompanhei as transformações na produção e circulação do conhecimento numa crise global de saúde através de observação em lugares não-digitais como fóruns científicos, contextos clínicos, grupos de ativismo. Ainda no registo não-digital, analisei a confluência de saberes e práticas e a erosão de algumas fronteiras - como o ativismo pressionando o laboratório, negociando estratégias clínicas e políticas públicas para acesso a conhecimento e tratamentos -, mas também a fortificação de outras fronteiras cognitivas. Destas destaco a prevalência, na medicina das doenças infecciosas, de uma matriz belicista, com seu vocabulário de ataque e contra-ataque, de arsenal e munições, de exército com soldados de combate e torres de defesa e vigilância.

Embora na biologia se anunciasse já a possibilidade de usar outros modelos cognitivos para pensar as infecções, como veio a acontecer no século XXI, o modelo de ataque, defesa e contra-ataque estava tão naturalizado no século XX 
que enformou toda a política de AIDS. Entender as raízes e poder dessa naturalização levou-me ao ciclo de pesquisas seguinte, com o qual passei da AIDS a epidemias mais antigas. ${ }^{3}$

\section{Medicina e império: o contexto do modelo bélico}

O novo ciclo projetou-me para o passado, já que a hipótese de pesquisa para a onipresença do modelo de guerra para pensar infecções apontava para as suas raízes na medicina tropical, antepassada imediata da infectologia. A medicina tropical consolidara-se nos finais do século XIX e inícios do XX, predominantemente em cenários de conquista - tanto em impérios coloniais propriamente ditos, como os da imposição europeia na Ásia e África, como na conquista de fronteira interna enquanto projeto nacional, como acontecia no Brasil. O exercício da medicina tropical era também um exercício de conquista, expansão, dominação, ou "pacificação" por meio de guerra; a permeabilidade da clínica ao vocabulário militar foi o caminho da sua naturalização.

Nesse contexto dediquei-me ao estudo de doenças como a varíola, cólera e peste, e parcialmente também da malária, articulando-me com a literatura de história social da medicina (Packard, 1989; Rosenberg, 1988), com a de medicina e império (Arnold, 1988; Curtin, 1998; MacLeod; Lewis, 1988; Manderson, 1996), sobretudo para a Ásia do Sul (Arnold, 1993; Bala, 1991), e com a de medicina na construção de nação, sobretudo para o Brasil (e.g. Hochman, 1998; Lima, 1999). Tendo encontrado nos relatórios de saúde coloniais de Goa materiais empíricos que permitiram de imediato desenvolver e fundamentar a minha proposta analítica, resumi o problema num pequeno artigo (Bastos, 1998) e passei a outras frentes, ainda no âmbito da medicina colonial: o ensino e institucionalização da medicina europeia na Índia (Bastos, 2004, 2007a) e a instrumentalização

3 Indiretamente continuo a acompanhar a AIDS na supervisão de estudantes e colegas que abordam as dinâmicas entretanto criadas no acesso aos medicamentos antirretrovirais, a sua circulação internacional, as escolhas de microalcance e negociações intrafamiliares e intragrupos nas comunidades afetadas, com novas resistências a medicamentos, patologias múltiplas e crónica escassez de meios. Entre muitos, destaco o trabalho em curso de Rafael Agostini (ENSP-Fiocruz) sobre a assistência ao HIV no SUS do Grande Rio e de Francesca Cancelliere (ICS-ULisboa) com jovens nascidos HIV-positivos no sul de Moçambique. 
dos médicos goeses para a consolidação da administração europeia em África (Bastos, 2001, 2007b). Foi no desenvolvimento desse estudo que se me pôs a questão que me levaria ao estudo das migrações entre impérios concorrentes, contexto no qual encontrei as febres a bordo que discutirei mais adiante.

A minha estadia na história social da medicina e nos estudos de medicina e império foi feliz e produtiva, mas a antropóloga que predominantemente sou sentia falta da dimensão experiencial da sociedade e cultura captada na etnografia. Em parte devido às fontes que utiliza, em parte pela própria lógica disciplinar, a história social da medicina está relativamente condicionada ao cânone memorialista de narrativas de descoberta, ao qual acrescenta o contexto político, a articulação entre as dinâmicas de desenvolvimento médico científico e as dinâmicas políticas de nação, classe, estratificação; mas incluir o contexto não chega para nos aproximarmos da dimensão experiencial dos sujeitos e da plenitude metodológica da etnografia que tanto prezamos na antropologia, pelo que se impõe trazer a perspetiva etnográfica à interpretação do arquivo (Ladwig et al., 2014; Stoler, 2010).

\section{Materialidades, visualizações, regimes do poder/saber: da água à sífilis}

Por outro lado, uma interessante dinâmica de mudança afetava a história da medicina durante o período em que a frequentei com mais assiduidade: uma aproximação aos estudos de ciência, e vice-versa. Várias associações de estudos de ciência acrescentaram um $M$, para medicina, ao seu $S \& T$ de ciência e tecnologia (Science and Technology). Também a antropologia médica abraçou algumas perspetivas do STS (Science and Technology Studies). Vários dos caminhos que tinha trilhado anteriormente de modo separado estavam agora a confluir, facilitando o meu regresso à antropologia como âncora dominante, e almejando à convergência multidisciplinar necessária ao estudo da experiência de saúde, sofrimento, doença, práticas e conhecimento médico - sobretudo nas epidemias.

Outras transformações ocorriam na antropologia, incluindo a curiosa virada para o pós-humano e pós-social, com a entrada em cena da agência não-humana, das antropologias simétricas de humano e não-humano, o enfoque nos objetos, incluindo instrumentos científicos, micróbios, vírus e vetores 
(e.g. Segata, 2017). Tudo isso foi estimulando o campo e até divertindo os pesquisadores e público em performances e títulos que usavam a ironia e como propiciadores cognitivos da inovação (e.g. Latour, 1991). Creio todavia que a inflexão dessa virada, que deveria ser assimptótica à inquestionável dimensão da experiência, do social, da dimensão coletiva, foi muitas vezes mais que assimptótica, cortando-a concorrencialmente - e gerando justas questões sobre o que fazemos quando nos deparamos com mais teses e artigos de antropologia sobre objetos que sobre a experiência coletiva humana.

Apesar do meu ceticismo não deixei de me envolver com alguns objetos-objetos, ou materialidades, que me levaram a estudos de outras dimensões da experiência de saúde. Um deles foi a água termal, que me abriu os campos das condições crónicas e da produção de lazer terapêutico (Bastos, 2011c, 2011d; Quintela, 2011a, 2011b). O outro foi uma coleção de moldagens dermatológicas com visualização tridimensional de patologias cutâneas, frequentemente expressões de sintomas de sífilis no rosto, nos genitais, membros, tronco humano (Bastos, 2011b, 2017; Bastos; Delicado; Matos, 2014; Delicado; Bastos, 2014). E assim a sífilis se tornou a epidemia seguinte no meu ciclo de trabalhos.

Do ponto de vista da pesquisa social em epidemias e doenças infecciosas, 0 estudo da síflis permite-nos ir mais longe que o de muitas outras patologias; é uma moléstia relativamente próxima de nós, e não de um passado remoto; mobilizou instituições e dispositivos que nos são caros enquanto teóricos do social, da micropolítica, da subjugação; presta-se a exibir a inscrição das clássicas variáveis sociais de género, classe, lugar; é denso ponto de passagem entre a ordem política, o sexo, a prostituição, a cidade, a família, a polícia, as prisões, os hospitais, os hospitais-prisão; foi alvo de uma especialidade clínica e científica - a sifilografia, dentro da mais ampla dermatovenereologia; foi território de disputas franco-alemãs pela supremacia académica ao longo do século XIX; foi matéria central na chamada "troca colombiana" (Crosby, 1972), em que os europeus terão levado para as Américas a varíola, a gripe e o sarampo, trazendo no regresso a sífilis, ou pelo menos a variedade letal que grassou pela Europa a partir do século XVI e teve nomes vários, de mal de Nápoles a mal gálico, lues, sífilis, etc. Por estar nesses interstícios e charneiras do biológico, social, político, cultural, legal, não faltaram os trabalhos de qualidade sobre a sífilis (Brown, 2006; Carrara, 1996; Levine, 2003; Saraiva, 2009 - entre outros). Inspirada nessas perspetivas, concebi um projeto para prosseguir no estudo da sífilis 
pelo ângulo dos hospitais-prisão, uma vez que, em paralelo com o que se passava na nascente psiquiatria, também na sífilis se criaram muros controlados pela polícia para separar as pessoas afetadas e o público; assim acontecia nas enfermarias-prisão de Santa Maria Egipcíaca e de Maria Madalena no hospital do Desterro, onde eram contidas, por ordem da polícia sanitária de Lisboa, as prostitutas que não passavam no exame venéreo (Bastos, 2011b). Essa pesquisa ficou adiada por ter começado entretanto um outro projeto de grande ambição, no qual se integra o estudo das epidemias a bordo.

\section{Corpos em trânsito I: plantações e produção de categorias racializadas}

A pesquisa que hoje desenvolvo com o projeto "A cor do trabalho: as vidas racializadas dos migrantes" é sobre trabalho, migrações e racializações. O conceito central é que as categorias raciais que se consolidaram nos diversos universos das economias de plantation - e delas foram exportados para outros mundos - foram geradas em função das hierarquias de trabalho na produção. O conceito de que foi a escravização e o trabalho escravo que produziram a categoria "negro", como aponta Edgar Thompson já nos anos 1930 (Thompson, 1975, 2010), e reforçam Barbara e Karen Fields nos dias de hoje (Fields; Fields, 2012), é aqui ampliado de modo a abarcar mais grupos e dinâmicas de racialização, abrangendo vários contextos e mobilizando vários pesquisadores. Hoje vou abordar dois desses contextos, ambos ligados à economia de plantação de açúcar: a Guiana colonial britânica e o Hawaii, primeiro enquanto reino, depois enquanto território anexado aos Estados Unidos. Em ambos os casos vou centrar-me na migração de ilhéus portugueses contratados como força de trabalho para os canaviais e engenhos de açúcar. É no seu transporte, na longa viagem de açorianos e madeirenses para o Hawaii, que encontrei o registo de dezenas de mortes infantis por sarampo que dão título a este artigo. Antes de as descrever, umas notas sobre o contexto.

Que migrantes portugueses são estes, contratados, força de trabalho nos campos de cana do açúcar e seus engenhos, levados para lugares distantes em impérios concorrentes, em grande número, todavia apagados da narrativa historiográfica que para Portugal se centra nas questões de império no Brasil e 
em África, trazendo para a discussão também a Índia e o Oriente em geral, e os descobrimentos, de modo a dar um lastro de tempo, espaço e mérito a esse império?

Sabemos hoje que a história de Portugal e portugueses no século XIX é bem mais complexa que a da narrativa de construção de um império em África ligada a anteriores aventuras imperiais; para usar o belo título do escritor português autoexilado em Nova York José Rodrigues Miguéis (2005) para a vida migrante, é como um espelho poliédrico, reflete coisas opostas em simultâneo; é a situação irónica, como aponta Newitt (2015), de Portugal se promover enquanto nação colonizadora e ao mesmo tempo ser o fornecedor da força de trabalho nas colónias de outros impérios.

Desde pelo menos 1835, na sequência da emancipação dos escravizados nas colónias britânicas, Portugal fornece mão de obra a nações e impérios concorrentes. Data desse ano a primeira viagem registada com madeirenses destinados às plantações da Guiana Britânica. Iam no veleiro inglês Louisa Baillie (Menezes, 1986, p. 5), em condições de recrutamento obscuras (Spranger, 2017a), não sabendo muito bem para onde iam nem conhecendo a dureza radical que os esperava em terra. Esse trânsito prolongou-se, estendeu-se a outras colónias britânicas no Caribe, e, a partir de 1878, já com outra situação contratual, expandiu para uma rota mais ambiciosa, a das plantações do Hawaii (Bastos, 2018a; Caldeira, 2010; Spranger, 2017b).

\section{Corpos em trânsito II: eugenismo, império e biopolíticas concorrentes}

Como cheguei a esses fluxos, quase invisíveis na historiografia estabelecida, predominantemente focada no império e no chamado mundo lusófono? Quando expandia o estudo da medicina colonial deparei-me com uns estudos antropobiológicos de um médico de Goa em serviço no sul de Angola, obcecado em descrever um grupo que designava como eurafricanos, ou luso-angolenses, que na sua opinião constituíam a prova viva de como os portugueses se adaptavam à vida nos trópicos mantendo linhagens puras, sem se misturarem com os locais - no oposto do que sustentava Gilberto Freyre (Bastos, 2003, 2005, 2019a; Correia, 1925, 1934). Esse médico, de nome de autor Germano Correia, 
endossava as correntes eugenistas e racialistas dos anos 1920-1930. Dedicou grande parte da sua vida a provar a pureza racial dos lusodescendentes na Índia e a contrariar o que então era tido como estigma de miscigenação. As suas obsessões levaram-no a escrever e publicar tanto que se tornou minha fonte indireta para vários assuntos, incluindo sífilis e comércio sexual (Correia, 1938). Foi o seu intrigante estudo sobre uma população branca do sul de Angola que me levou a pesquisar mais aprofundadamente as suas circunstâncias e, no processo, dar-me conta da existência de um complexo enredo de império e migrações por mapear.

Abreviando uma história contada noutros lugares, temos que nos anos 18841845 um contingente de centenas de madeirenses foi transportado da sua ilha natal para o porto de Moçâmedes, hoje Namibe, no sul de Angola, a bordo do navio Índia - e com o nome de Maria Índia seria batizada a menina que nasceu durante a viagem, particularidade que me levou a mais conexões e cruzamentos auspiciosos (Bastos, 2008, 2009, 2011a). De Moçâmedes foram transportados em carros bóer através da serra da Chela até ao planalto da Huíla, de altitude de 2000 metros, e aí fundaram várias comunidades: Lubango, Huíla, Chibia, Humpata. Colocados numa fronteira de dificuldades, sobreviveram e os seus descendentes foram medidos pelos compassos antropométricos de Correia cerca de 40 anos depois. A sua saga foi narrada como pioneirismo colonizador, antecedendo os contingentes mais organizados de colonos portugueses que ali chegariam apenas na segunda metade do século $\mathrm{XX}$ - e que aos primeiros racializariam como "brancos de segunda", ou "brancos da terra", secundarizando-os na linguagem hierárquica que dava primazia aos recém-chegados de Portugal.

Apesar da pujança pioneirista-heroica que transparece nas fontes secundárias, o estudo crítico das fontes primárias indica que estava em causa algo mais complexo que um episódio planeado de colonização visando a consolidação de um império em África. Na minha interpretação, a colonização do planalto sul de Angola com madeirenses em 1884-1885 e anos subsequentes foi sobretudo uma manobra de reencaminhamento, para território de jurisdição nacional, de migrantes que saíam dos espaços nacionais e do império. Os ilhéus, e sobretudo os madeirenses, fugiam do país e embarcavam para contratos nas plantações de açúcar estrangeiras, de que se destacavam os já referidos Guiana Britânica e Hawaii. Apelos ao reencaminhamento desses colonos para lugares sob jurisdição portuguesa revelam a preocupação de alguns governantes 
e parlamentares portugueses quanto à sangria que levava os nacionais para impérios concorrentes e os subtraía do projeto de império que se alimentava no rescaldo da independência do Brasil. Nos documentos em prol da transferência dos portugueses da Guiana para África descrevem-se com dramatismo as más condições vividas nos impérios estrangeiros. ${ }^{4}$ Os equivalentes para os portugueses do Hawaii são menos dramáticos, mas igualmente aventam transferências para lugares sob controle português (neste caso, Timor), alimentando o tom patriótico-imperial de finais do século XIX. ${ }^{5}$

\section{Corpos em trânsito III: quase-esqueletos a bordo e febres no destino}

A Guiana Britânica acolhe madeirenses desde 1835 com um cenário radical de quase morte por exaustão laboral e insalubridade nos lugares onde antes estavam africanos escravizados. Depois da abolição (1808) e emancipação (1833-1834), os donos de plantações baseadas em trabalho escravo foram compensados monetariamente pelo governo britânico e procuraram substituir a força de trabalho através de redes de recrutamento que atuavam em diversos lugares, incluindo a costa de África, na ilha de Santa Helena e nas capturas a barcos escravistas de outras nações. A Madeira contava-se entre esses lugares, pois tinha fortes conexões com as redes comerciais britânicas; estava nas rotas comerciais entre as ilhas britânicas e o Caribe, tinha várias delegações comerciais inglesas, e a influência dessas conexões chegava ao ponto de conseguir o recrutamento de centenas de madeirenses a embarcar para as plantações.

Ao longo do século XIX, muitos homens e mulheres madeirenses - e alguns das ilhas dos Açores, Canárias, Cabo Verde - seguiam para esse destino, por

4 Arquivo Histórico Ultramarino, Conselho Ultramarino, Índia, cx. 14, doc. 453, "Sobre o estado de miséria em que se acham os colonos portugueses em Demerara", e também Arquivo Histórico Ultramarino, Conselho Ultramarino, Reino, cx. 2, doc. 32, "Emigração de madeirenses e açoreanos para a Guiana Britânica (Demerara)", 1852. Agradeço a Marta Macedo, Marcelo Moura Mello e Nicholas Miller as discussões ocorridas a esse respeito em 2018-2019.

5 Arquivo Histórico Diplomático, Ministério dos Negócios Estrangeiros, Lisboa, Consulado de Portugal em Honolulu, cx. 624, 1896-1913, f. 9/34, Carta do Consul Antonio de Souza Canavarro ao Ministro e secretário de Estado dos Negócios Estrangeiros Mathias de Carvalho e Vasconcellos, 14/11/1897. 
vezes fugindo a condições extremas, outras vezes constrangidos, se não mesmo capturados, outras vezes explorando possibilidades de melhorar a vida. Nas plantações da Guiana, ou Demerara (uma das suas três províncias, junto com Essequibo e Berbice), mudara o regime legal que relacionava senhores e escravos, donos de terra e trabalhadores, mas quase tudo o mais se mantinha intacto: a materialidade da produção do açúcar, a brutalidade dos ritmos, o fardo do trabalho, o pesado clima equatorial, as febres, a precariedade da habitação, da saúde, da vida em geral, e não é de excluir que muitos castigos corporais tenham persistido no cenário da plantação. Os madeirenses morriam em grande número, mas continuavam a chegar, e continuavam, regressando alguns, entusiasmando outros com as histórias de sucesso, escondidas as de insucesso.

São poucas as fontes para conhecermos aprofundadamente a materialidade da experiência corporal, da saúde e doença enquanto experimentadas, narradas, analisadas, tratadas, lembradas. Muito do que sabemos, para além das monografias de Mary Noel Menezes $(1986,1992)$, de uma breve entrada de enciclopédia por Ana Isabel Spranger (2017a), e de uma massa de documentação britânica em estudo, ${ }^{6}$ reporta-se a duas ordens de documentos oficiais em que é dado espaço a comentários pessoais que não ficaram "inscritos" na memória coletiva e na narrativa histórica dominante. A primeira consiste na correspondência consular entre a Guiana Britânica e Lisboa, em que sobressaem as indicações de dificuldades encontradas pelos ilhéus portugueses à chegada à Guiana e as condições extremas do trabalho nas plantações, a mortalidade, e a centralidade dos madeirenses na sobrevivência da economia do açúcar nesse período. ${ }^{7}$ A segunda, mais concentrada no tempo mas densa em pormenor e comentário, consiste na correspondência de José Silvestre Ribeiro, governador da Madeira entre 1846 e 1852. Esses anos foram trágicos para a população da ilha - falta de mantimentos, efeitos de distúrbios políticos, e a subsequente

6 Destacam-se os relatórios parlamentares, "Accounts and papers of the House of Commons", para este período, e um relatório feito a pedido do parlamento, o "Dr Bunyon's report on the state of migrants", de 1848. Estou em processo de análise dessa documentação, no que conto com o qualificado apoio do pesquisador convidado Marcelo Moura Mello.

7 Arquivo Histórico Diplomático, Ministério dos Negócios Estrangeiros, Lisboa, Consulado Guiana Ingleza, cx. 700, f. 74; Arquivo Histórico Ultramarino, Conselho Ultramarino, Índia, cx. 14, doc. 453, "Sobre o estado de miséria em que se acham os colonos portugueses em Demerara", 1852. 
fome que fez alguns aceitarem partir a qualquer custo, muitas vezes sem saber para onde iam, nas condições mais obscuras. ${ }^{8}$ José Silvestre Ribeiro escreve emocionadas missivas ao seu ministro e refere o número de 40 mil madeirenses levados para as plantações. Poderá ter exagerado, e nunca chegaremos ao número exato dos que foram, uma vez que muitos partiram clandestinamente, escapando às malhas de contagem a bordo e à chegada.

É a esses anos que remonta a terrível viagem do Borderer, uma das poucas que conseguimos reconstituir a partir de fontes primárias graças a um documento encontrado no arquivo do Museu Marítimo Nacional em Greenwich, Reino Unido, numa pasta referente a um outro navio britânico, o Wampoha, também ele destinado a Demerara (Guiana). ${ }^{9} \mathrm{O}$ Borderer saiu do porto inglês de Bristol a 17 de maio de 1847, chegando à Madeira 11 dias depois. A 8 de junho encontramos o primeiro registo do troço Madeira-Demerara, que não está assinado e pode ter sido escrito pelo imediato, por um capelão, cirurgião, ou mesmo pelo comandante do barco. Os 250 emigrantes embarcados a bordo na Madeira são referidos como estando no mais radical estado de debilidade e fome, como "esqueletos" ambulantes, em "pele e osso". ${ }^{10}$ Logo na primeira hora de embarque nasce uma criança a bordo; a tripulação tem de se dedicar a cuidar dos passageiros, emergência maior e prioridade sobre a própria navegação; ao terceiro dia um homem atira-se ao mar na sequência de um ataque nervoso,

8 Arquivo Regional da Madeira, Correspondência para o Ministério do Reino do Governador Civil José Silvestre Ribeiro sobre a Emigração para Demerara, liv. 644, 1846-1851. Agradeço a Ana Isabel Spranger as discussões e análises cruzadas sobre o assunto.

9 Caird Library, National Maritime Museum, Greenwich, U.K., "Madeira-Demerara, Logbook for the Ship Whampoa". O Whampoa fizera a viagem em 1844-1845 e o registo de bordo refere-se sobretudo a pormenores técnicos da navegação. Em contrapartida, o registo do Borderer, sem referência no catálogo, mas incluído no maço, é de grande detalhe nas referências aos passageiros embarcados. Foi consultado pela primeira vez em março de 2017 e mais de dois anos passados não encontrei ainda equivalente para outras viagens. A ficha descritiva no interior do maço que contém um volume encadernado em couro: "Log of the ship WHAMPOA from Madeira to Demerara, London, Madeira and Demerara, from $29^{\text {th }}$ November $1844-8^{\text {th }}$ May 1845. Also log of the ship BORDERER from Demerara to London $12^{\text {th }}$ October $-10^{\text {th }}$ November 1845 , including four other voyages touching Deal, Madeira, Aden, Bombay, Singapore, Hong Kong, Whampoa, Bristol ending at Liverpool. These voyages begin from Deal in January 1846 ending at Liverpool $20^{\text {th }}$ November 1847. No name of keeper of this log."

10 "Men, women, children, most of them in an apparent state of starvation, literally nothing but skin \& bones" - Caird Library, National Maritime Museum, Greenwich, UK, Log of the Ship... reg. June $8^{\text {th }} 1947$. 
sendo resgatado mas passando o resto da viagem em camisa de força. Mais dois passageiros morrem de debilidade. Só nos dias 13 e 14 se regista alguma estabilização, saindo-se do estado de emergência que a desesperante subnutrição dos passageiros impunha, e é retomada a normalidade da navegação e, num momento de fulgor celebrativo, passageiros e tripulantes cantam e dançam juntos. Mas a alegria dura pouco, pois logo são assolados por uma grave disenteria coletiva, que colhe mais algumas vidas de crianças e adultos. A 19 de junho dá-se um novo nascimento. Morreu-se e nasceu-se a bordo do Borderer, como se nascia e morria nas viagens que transportavam os trabalhadores vinculados da Índia para o Caribe descritas por Gaiutra Bahadur (2014) e por Kevin Brown (2013). A 30 de junho está registada a chegada e o pedido de um piloto do porto; as coordenadas geográficas de $6^{\circ} 44 \mathrm{~N}$ e $57^{\circ} 6 \mathrm{~W}$ indicam a localização de Fort Wellington, Demerara, entre a capital Georgetown e as plantações de New Amsterdam e Roussignol. Em breve os passageiros seriam desembarcados para estas e outras plantações, onde muitos morreriam ainda de disenterias e outras febres, outros sucumbiriam à brutalidade do trabalho e outras violências, outros ainda continuariam prosseguindo com as suas vidas na agricultura ou no comércio no qual em poucos anos se tornariam o grupo predominante.

Como argumenta Mustakeem (2016, p. 7) em Slavery at sea, o regime da plantação começava bem antes da chegada, e o navio escravista do século XVIII era já uma incubadora de desumanização que viria a ser levada a extremos na plantação propriamente dita. Ou, acrescente-se, já a bordo estavam em jogo os mecanismos de racialização que tomariam corpo extremo no regime da plantação. Já a bordo se desenhavam as relações violentas de subjugação e alienação da possibilidade de controle do próprio corpo, já a bordo se usava o chicote e outras violências como modo de dominação, o abuso sexual, o terror, gerenciado de modo a vilificar mas preservar, pois tratava-se de carga, valor, que precisava de chegar ao destino em condições de venda e lucro. E para o garantir existiam também técnicas de preservação da vida, de exercício obrigatório, e até de dança mandatória (Mustakeem, 2016).

Autores como Kevin Brown (2013) e, mais recentemente, Nicholas Miller (no prelo) dedicaram-se a discutir que transições se deram quando os mesmos navios que transportavam escravizados passaram a transportar a força do trabalho não escravizada que se seguiu à emancipação: os vinculados da Índia, os capturados em blackbirding do Pacífico Sul, os capturados e recrutados da 
Madeira que agora abordamos, e também dos Açores, Cabo Verde e Canárias. Sendo pouquíssimos os registos de bordo encontrados para essas viagens, não temos suficiente acesso a esse universo e, tal como faz a autora de Coolie woman (Bahadur, 2014), podemos recorrer à especulação informada e controlada com base em documentos que se aproximam das circunstâncias que buscamos. É assim algo especulativa a interpretação para as anotações da viagem de 1847 do Borderer. Não sabemos se a comoção que nestas perpassa a respeito do estado dos migrantes é de natureza comercial ou humanitária; não sabemos se a assistência que lhes é dada pela tripulação para sair do estado de quase morte em que se encontravam assenta em princípios humanitários, ou num cálculo de gestão da força de trabalho, ou em ambos. Devemos ficar atentos ao aparecimento de mais anotações e procurar o caminho seguido por esses migrantes nas plantações para onde foram contratados. Não foram caso único: essa viagem seria repetida por muitas outras.

Dessa e de muitas outras viagens que se seguiram entre a Madeira e Demerara se vão somando os ilhéus portugueses na Guiana Britânica, perfazendo dezenas de milhar, sendo que nem todos são trabalhadores contratados nas plantações. Quando os contratos terminavam, muitos tentavam a sorte no comércio, em modo ambulante ou estabelecendo armazéns e lojas; competiam nessa frente com os africanos libertos - por vezes com atritos, como aquando dos chamados "motins portugueses" (Mello, 2019; Menezes, 1992; Moore, 1975; Rodney, 1981) - e as histórias de fortuna que contavam atraíam mais conterrâneos (Spranger, 2017a). Alguns chegaram à Guiana sem ter de enfrentar a dureza da plantação e entravam diretamente no comércio. Vários tiveram sucesso, tornaram-se um elemento indispensável do mosaico local, personagens secundárias mas onipresentes na literatura. V. S. Naipaul, descrevendo a mesa de refeições dos passageiros de primeira classe a bordo do Francisco Bobadilla em 1960,11 e elaborando sob os cromatismos racializantes dos diferentes lugares do Caribe, refere "um homem de cor", descendente de africanos

11 Trata-se da viagem do escritor entre a Inglaterra e a Trinidad, em 1960, a convite do primeiro-ministro e intelectual Eric Williams, também da Trinidad, para que testemunhasse as transformações pós-coloniais em curso e escrevesse sobre elas. Naipaul visitou também a Guiana Britânica em vésperas da independência, o Suriname e várias ilhas do Caribe, descrevendo a experiência no seu proverbial estilo cáustico e nem sempre do agrado dos políticos anticoloniais que o acolheram (Naipaul, 1996). 
e europeus, mais velho, que teria usado impropérios antinegros próprios da linguagem hierárquica cromatizada corrente no Caribe mas surpreendente para quem, como o escritor, vivera recentemente num regime de racismo binário com poucas nuances; a mulher desse homem, espanhola, que não usava a língua da tripulação, também espanhola; Correia, um português da Guiana Britânica, e Philip, o qual "vinha da Trinidad, onde tinha um 'pequeno negócio', e podia ser branco ou português ou de cor ou judeu" (Naipaul, 1996, p. 6, tradução minha) - e se veio a revelar afinal português, num episódio em que o derrogatório potogee é lançado à mesa, e a partir do qual não se toca mais no assunto (Naipaul, 1996, p. 8-9).

Os portugueses estabeleceram-se na Guiana, e no Caribe em geral, e noutras sociedades de plantação predominantemente anglófonas, como uma categoria à parte. São até hoje uma das seis "raças" da Guiana, lado a lado com brancos, negros, indianos, chineses e ameríndios, para referir as categorias locais em uso ainda hoje. Nos anos que antecederam o fim do colonialismo, com lutas intensificadas entre vários partidos, muitos portugueses da Guiana procuraram novas rotas e estabeleceram-se no Canadá.

\section{Corpos em trânsito IV: a febre rumo ao Hawaii}

O trânsito dos ilhéus portugueses para as plantações de açúcar no Hawaii nasce em outra conjuntura económica e enquadramento laboral. No Hawaii, ao contrário do mundo do Caribe, não tinha existido escravização de africanos para mão de obra nos canaviais e engenhos. A questão que levou a promover a deslocação de portugueses, de tão longe, não foi a rápida substituição dos escravizados por quem estivesse à mão das rotas Inglaterra-Caribe. O Hawaii tinha uma peculiar conjuntura, combinando o grave declínio demográfico que ao tempo afetava a população local, as políticas de reposição de contingentes populacionais equacionadas, e a vontade explícita, durante alguns períodos, de conter a imigração chinesa e japonesa, somando ao preconceito preexistente o temor de ocupação por nações da Ásia. Foi assim com apoio do governo do Hawaii e da associação de proprietários das plantações que se promoveu a vinda de migrantes portugueses das ilhas da Madeira e Açores. Entre 1878 e 1913 viajaram quase 20.000, dos quais poucos regressaram. Muitos ficaram 
no Hawaii, e destes muitos partiram para a Califórnia no termo do contrato (Bastos, 2018a, 2019b; Caldeira, 2010; Spranger, 2017b).

Estando fora do circuito conhecido da historiografia de Portugal e império, essa migração de larga escala teve grande impacto demográfico, económico e cultural nas sociedades de chegada. Os portugueses nas plantações do Hawaii e da Guiana constituem um excelente caso para estudar a dinâmica de racializações, uma vez que, tendo entrado como força de trabalho, esses migrantes foram racializados como tal, diferentes de brancos (Geschwender; Carroll-Seguin; Brill, 1988), diferentes de africanos escravizados, diferentes dos asiáticos e ilhéus do Pacífico Sul no Hawaii, ou dos sul-asiáticos que formaram o maior contingente de trabalhadores vinculados na Trinidad e Guiana. Constituíram-se como portugueses, considerados nação, raça, etnicidade, nome de comida, e outras qualidades que não têm necessariamente vínculo com Portugal propriamente dito.

E é no longo trânsito para o Hawaii que viajam as famílias, muitas vezes numerosas, com adultos e crianças. Em algumas das viagens irrompe o sarampo, e com ele a luta contra a febre, a perda, a devastação da morte, os inquéritos à chegada, e - pasme-se - a culpabilização das mães. A esses episódios vou agora referir-me.

Foi na secção Pacific-Hawaiiana da biblioteca Hamilton, na Universidade do Hawaii em Manoa, quando em 2017 pesquisava sobre os portugueses no Hawaii, que pela primeira me deparei com a notícia de cerca de 50 mortes de crianças no navio Bordeaux, que trazia famílias madeirenses para as plantações de açúcar do Hawaii. ${ }^{12}$ Munida do ano e do nome do barco, parti para a pesquisa de mais informação em jornais da época, arquivos de correspondência consular, registos sanitários. Encontrei uma referência semelhante, e para o mesmo ano, porém com diferente nome de barco. Continuando a pesquisa, encontrei uma terceira referência, ainda a epidemia de sarampo, também referindo um montante superior a 50 crianças mortas, e notícia suficientemente fora do comum para chegar aos jornais, indicando que a pedido do cônsul se prosseguiu para inquérito.

12 A notícia fazia parte de uma compilação de transcrições de recortes de jornais por um investigador, fonte indicada, entre outras, pela generosa bibliotecária e arquivista Jodie Mattos. 
Essa pesquisa foi morosa e complexa, uma vez que a documentação relativa ao período da monarquia havaiana não foi universalmente centralizada no Arquivo Estadual do Hawaii em Honolulu; com efeito, a documentação dos serviços de saúde e emigração está praticamente ausente do que é para os demais sectores um acervo muito rico e bem preservado. ${ }^{13} \mathrm{O}$ cruzamento de várias fontes permitiu porém reconstituir um quadro em que três dos navios transportando famílias das ilhas portuguesas - o City of Paris, com madeirenses e açorianos, o Bordeaux e o Hankow, com madeirenses - tiveram ocorrências de acima de 50 mortes infantis por sarampo. Esses dados convergem com o que foi compilado por Susana Caldeira (2010, p. 91) nos arquivos do Funchal e no Arquivo Histórico Diplomático, em Lisboa. Numa discreta nota de rodapé, devidamente referenciando como fontes a correspondência do cônsul português em Honolulu António Canavarro, complementada com notícias da imprensa madeirense à época, Caldeira aponta que no vapor Hankow, em 1883, "morreram 54 crianças, vítimas de uma epidemia de sarampo", e no ano seguinte, em 1884, na viagem do vapor inglês City of Paris, o sarampo teria atacado "cerca de 400 pessoas, tendo sido fatal para dois adultos e 53 crianças". Aponta ainda que, segundo o cônsul, "a ilha da Madeira vivia a braços com um surto de sarampo, e a descoberta de cinco casos a bordo não foi impedimento para a saída do navio do porto do Funchal". Acrescenta que "o sarampo também foi causa de grande mortalidade a bordo do vapor francês Bordeaux (1884)" e que este, "apesar de apresentar boas condições de higiene e ventilação", foi lugar de morte de "três adultos e 69 crianças, entre 1 e 2 anos de idade"; e que o cônsul observou "que as crianças não possuíam o vestuário necessário que pudesse resguardá-las do frio intenso que se fazia sentir durante a travessia oceânica". Dessa transcrição sobressai também uma nota do cônsul alertando as autoridades "para a necessidade de providenciar mais espaço no hospital dos navios de emigrantes e de empregar mais pessoal médico e de enfermagem". O Bordeaux fora já alvo de especial atenção no Funchal. O vapor teria inicialmente aceitado mais de mil passageiros, mas uma vistoria promovida pelo governo civil fizera reduzir o número para 760 , de modo a cumprir a legislação vigente, pelo que foram desembarcados 440 passageiros,

13 A pesquisa de fontes incluiu tentativas vãs de aceder a coleções que pudessem ter permanecido no Queens Hospital em Honolulu, onde uma pequena biblioteca de história médica se organizou. 
"sendo que dos embarcados já tinham falecido duas crianças, uma de pneumonia e outra de fraqueza" (Spranger, 2017b). Os passageiros retirados foram alojados num armazém e compensados monetariamente. Alguns deles embarcariam no Daca, um veleiro que saiu pouco depois mas demoraria o triplo do tempo a chegar a Honolulu. Não sabemos se algum destes morreu com sarampo, mas sabemos que no Bordeaux quase 70 crianças sucumbiram.

\section{A morte infantil e as mães: revisitando uma controvérsia na antropologia}

Depois de muito procurar os dados relativos aos inquéritos sobre o que se passara a bordo das viagens em que mais de 50 crianças tinham perecido, em que se avolumavam as queixas dos emigrantes sobre maus-tratos a bordo, insuficiência de alimentação, condições extremas, cheguei a uma singular e preciosa transcrição dos resultados do inquérito, incluída no relatório da comissão de imigração para os anos de $1884-1886 .{ }^{14} \mathrm{O}$ documento confirmava que tinham ocorrido dezenas de mortes, e que a epidemia de sarampo tinha atingido quase todas as 400 crianças a bordo; que depois de analisados os dados, se concluía que a comida prevista para cada passageiro era adequada e variada. Mais se concluía que a razão pela qual tinha havido tantas mortes, tantas febres infantis, se devia à inadequação dos cuidados das mães, as quais, ditas ignorantes, não tinham levado suficiente agasalho para proteger as crianças e, por negli-

14 “Hawaii Bureau of Immigration Report 1884/86", Hawaiian-Pacific Collection, Hamilton Library, University of Hawaii at Manoa, consultado em outubro de 2017. Para o City of Paris existe um conjunto de depoimentos resultante do inquérito aos passageiros em que vários declaram que tiveram suficiente comida ao longo da viagem; os documentos permitem ainda perceber que além do sarampo houve também uma epidemia de varicela, mas para esta fora aplicadas vacinas - Hawaii State Archives, FO \& Ex 31 1884, Immigraton jan-jun, "Evidence taken June $17^{\text {th }}$ and subsequently at the Enquiry into the Causes of the Great Mortality among Children during the Voyage of the SS City of Paris". Temos ainda as inúmeras cartas do cônsul português António de Souza Canavarro exprimindo a sua preocupação com o que se passara a bordo desses três navios com base nos depoimentos de alguns passageiros, consultáveis nos arquivos do Ministério dos Negócios Estrangeiros em Lisboa e no Arquivo do Estado do Hawaii em Honolulu, e finalmente a compilação para apresentação parlamentar “Documentos apresentados ás cortes na sessão legislativa de 1885 , pelo ministro e secretário d'estado dos negócios estrangeiros, negócios consulares e comerciais, secção VI, emigração portuguesa para as ilhas havaianas", Lisboa, Imprensa Nacional, 1885. 
gência, as teriam exposto, sem a devida proteção, aos ventos polares ao dobrar o cabo Horn..$^{15}$ Por essa razão, segundo o relatório, a responsabilidade caía nas mães, na sua falta de cuidado, ignorância, inadequação, comportamento errado, e não nas questões que hoje discutimos no âmbito da biossegurança.

Esse ponto permite cruzamentos múltiplos com a etnografia e a saúde pública, e recorda uma controvérsia da antropologia médica em finais do século XX em torno de uma monografia sobre a morte infantil no nordeste brasileiro e a suposta passividade das mães (Scheper-Hughes, 1992); ou as análises da mortalidade infantil nas comunidades de migrantes nos inícios do século XX nos Estados Unidos, que levavam a comentários racializantes e a reações das comunidades (Bastos, 2018b).

Responsabilizar os mais próximos da morte e doença pela sua ocorrência por negligência, indiferença, ignorância e inadequação é um velho lugar-comum de escusa à abordagem de elementos de ordem estrutural e determinantes sociais da morbilidade e mortalidade. Ontem e hoje encontramos padrões de culpabilização que não apenas apontam para escolhas individuais, mas ainda patologizam grupos escondendo-se numa linguagem emprestada às ciências sociais: onde ontem se falava de ignorância e inadequação, ou de características de "raça", extensíveis a nações, hoje encontramos, para o mesmo efeito, alusões a padrões culturais, e neles se investem os mesmos preconceitos que outrora apareciam racializados. Apontar mães "que não choram" por presumidas razões culturais ecoa as acusações de inadequação das mães que deixavam as crianças no convés sem agasalho, como no relatório do inquérito à mortandade nas malogradas viagens dos vapores de emigrantes da Madeira. Mais perto da experiência estão as cartas de outros passageiros relatando o sofrimento duplo dos pais ao verem os filhos morrer e ao serem confrontados com o poder arbitrário dos encarregados a bordo, cujos abusos ampliavam a dificuldade de adiar ou amenizar a morte das crianças doentes.

15 "As to mortality among infants of whom there were 400 onboard, during the voyage of 68 days, measles had broken out, affecting nearly all the children. The mothers, owing to indifference or ignorance, often allowed their children to go about the decks scantily clad, therefore it could not be wondered at that diarrheas and lung troubles resulted from this exposure after measles. An adult ration was provided for each child over one year, and delicacies were served out to the sick - but neither delicacies nr medicines could avail children not taken proper care of by their mothers" (“Hawaii Bureau of Immigration Report 1884/86", p. 220). 


\section{Corpos cativos de fome, frio e abuso de poder}

Sobressai nessas travessias o facto de serem feitas em famílias, com muitas crianças. Não temos quadros semelhantes aos que Kevin Brown descreve para o transporte de indianos contratados - ou engajados, ou vinculados, como também se traduz indentured - quando em viagem para as plantações do Caribe, e onde irrompia frequentemente a cólera, com a brutalidade das cólicas, do vómito e da diarreia (Brown, 2013, p. 133), que tornavam os navios, de miasma ambulante que já eram, em foco aberto de infecção e morte. Tão-pouco temos os horrores descritos para o tráfico de africanos escravizados (Bolster, 1997; Christopher, 2016; Mustakeem, 2016; Rediker, 1989, 2007). Mas sofria-se, e em larga escala. Mesmo quando não havia epidemias, a viagem continha um elemento estrutural de incubadora de sofrimento. Os navios de emigrantes eram também lugares de constrangimento, contenção, abuso de poder. A função do navio foi-se transfigurando entre os momentos de navio escravista, de navio transportador de contratados-vinculados, e de transporte de emigrantes, mas manteve-se como mecanismo de produção de experiências corporais de alienação extrema e de reconfiguração do corpo.

No navio estavam contidos os fatores estruturais que, contra os esforços de mães e pais em proteger as suas crianças, acicatavam a experiência da doença e não permitiam mitigar os seus efeitos. Na documentação que reporta a experiência da vida a bordo em geral é recorrente a queixa sobre a má qualidade e inadequação da alimentação, a que nesses casos se somavam os abusos, por parte da tripulação, na distribuição dos víveres previstos. São múltiplas as queixas de fome, de degradação e insuficiência de alimentos, e dos subornos que circulavam para acesso aos alimentos sólidos e líquidos. Numa ilustrativa carta do passageiro madeirense José Melim transcrita no jornal O Direito, Funchal, a 15 de setembro de 1883, ficamos a saber da monotonia, insuficiência e pouca qualidade da comida, com batatas quase sempre podres; e que, tendo o sarampo irrompido a bordo, não ocorreu a melhoria alimentar que as circunstâncias impunham para lhe fazer face. A carta é igualmente interessante ao dar-nos conta das prepotências do "sobrecarga", o encarregado dos emigrantes, que exercia um poder paralelo ao do comandante do navio, que, em contraste, é descrito como um cavalheiro; o poder paralelo do sobrecarga acumulava abuso, mesquinhez e pequenas violências que chocavam o autor da carta. Quando as 
mães e pais aflitos perante o adoecimento dos filhos imploravam alimento, a essas súplicas "acedeu o sobrecarga, dando a cada criança um pedaço de pão, que elas comiam de uma só vez, e meio cálice de leite". Mais que veladamente, o autor da carta acusa o sobrecarga de ser corresponsável pela morte das crianças que, "inocentes, fracas, devoradas pela febre, morriam desta e da fome, desenvolvendo-se uma diarreia, que em poucos dias roubou aos desventurados pais emigrantes 58 filhinhos, e mais 5 que morreram no depósito quando aqui chegámos". O mesmo passageiro conta também que numa paragem um infeliz emigrante pediu um pouco de açúcar ao sobrecarga para fazer uma gota de chá para dar ao filhinho à beira da morte, e aquele, com indiferença, ordenou que, se 0 quisesse, que o comprasse. Acrescenta que um outro passageiro, também "conduzindo nos braços o filhinho a expirar, pediu-lhe uma gota de vinho, e o desumano sobrecarga deu-lhe vinagre!". Comenta, chocado, que é "horroroso, mas é verdade". E se algum passageiro reclamasse contra a comida ao sobrecarga, este mandava-o prender. Mas não ficaria impune esse tirano de bordo, pois em terra foi denunciado ao cônsul português em Honolulu (ver Caldeira, 2010, p. 259).

Como se vê nas cartas desse emigrante que testemunha a impotência de pais e mães cujos filhos fenecem de sarampo, os navios em viagem eram contentores de sofrimento humano, em que a estrutura de desigualdade era acicatada por indivíduos de desumanidade extrema e com poder para distribuir ou negar os poucos recursos que poderiam amenizar morte e sofrimento - pão, leite, vinho, remédios baratos e comuns mas inalcançáveis na suspensão de normalidade que é a vida no navio.

\section{Passagens e chegadas: o depósito de imigrantes e a estação de quarentena como dispositivos de biossegurança e fronteira política}

As famílias sofriam duras penas na viagem que as levava de um lugar de origem de onde queriam sair por razões múltiplas - falta de modo de vida para muitos, desejo de a melhorar para outros - até um destino que se prometia melhor, mas longínquo, a mítica Terra Nova com que era designado o Hawaii. Seis meses nos veleiros, oito ou mais semanas nos vapores, os emigrantes atravessavam dois grandes oceanos, passando duas vezes a linha do equador; tinham de aguentar 
a vida de porão, suportar a angústia da passagem; alimentavam expectativas, conviviam, enjoavam, passavam frio e calor, adoeciam, alguns nasciam, outros morriam, vivam enredos múltiplos envolvendo famílias, amantes, amigos e rivais, com disputas, festas, presépios, danças, música, entretenimento, aborrecimento.

De uma das viagens temos uma interessante descrição: trata-se de um diário de dois jovens madeirenses a bordo do Thomas Bell entre o Funchal e Honolulu em 1887-1888. Essa seria a última de um ciclo de viagens com ilhéus portugueses, que só viriam a ser retomadas muito mais tarde e, de modo sistemático, apenas em 1906 - agora em vapores de grande dimensão que traziam ilhéus, continentais e espanhóis (Bastos, 2019b; Caldeira, 2010; Miller, no prelo; Olim, 2019, Spranger, 2017b; Steele, 2013). Fechando o primeiro ciclo de migrações de portugueses para o Hawaii, a viagem do Thomas Bell é decerto a mais citada dessas viagens, graças ao esforço de João Baptista de Oliveira e Vicente de Ornelas que, estimulados pelo imediato do navio a registar o dia a dia, se tornaram os cronistas de bordo. Escrito originalmente em português, $o$ diário Destination: Sandwich Islands foi oferecido a um clérigo que partilhara a jornada, ficando esquecido até ao resgate e tradução para inglês e publicação pela sua herdeira Lucile Canario (d'Oliveira; d'Ornellas; Canario, 1970).

No diário perpassa alguma distância relativamente à massa de emigrantes contratados que viajavam em piores condições, mas não se traduz essa distância em sobranceria ao modo de Naipaul (1996); pelo contrário, é quase sempre com grande simpatia que estão descritos os episódios protagonizados pelos migrantes a bordo. A viagem foi particularmente atribulada, a ponto de à chegada terem dado ao cônsul um relatório de ocorrências para avaliação. E como se não bastasse, viram ainda protelada a verdadeira entrada em terra, pois a eles, como a outros antes e depois, esperava a estação de quarentena de Sand Island, no porto de Honolulu. E aí, como em muitos outros lugares do mundo, se dava a última inspeção.

Como em todos os portos a que chegavam migrantes, Honolulu tinha uma estação-depósito de imigrantes. Esta era conhecida pela sua idiossincrática construção de madeira, de que há testemunhos fotográficos a propósito de outros grupos que não os portugueses; não chegou porém até hoje, e no seu lugar erguem-se edifícios que até há pouco albergavam indústrias de enlatamento de ananás e entretanto se reconfiguraram para comércio. 
Outras estações de imigrantes chegaram até nós, memória expandida e perene do que era a última etapa da operação de filtragem dos corpos desejados para o trabalho, do que pode ser visto como duplo dispositivo de biossegurança e política migratória. Em lugares como Ellis Island, em New York, EUA, ou o Aapravasi Ghat, em Port-Louis, Maurícia, podemos encontrar memoriais da chegada em toda a sua dureza, enriquecidos por projetos museológicos que abordam a materialidade da viagem e da chegada (Peerthum, 2017).

Termino este artigo propondo trazer a reflexão para o presente imediato, quando as fronteiras se desmaterializam em processos digitais de controle e se rematerializam em campos de detenção, e quando a linguagem da biossegurança se entrecruza com práticas de necropolítica seletiva.

Enquanto parecia que era a partir de um ponto distante no tempo e espaço que abordávamos as passagens dos migrantes laborais, ou dos vinculados e dos escravizados, eis que desembocamos num presente de passagens perigosas e extraordinárias, fugas, exílios, travessias, afogamentos, perseguições, punições, arame farpado eletrificado, muros, campos de detenção, campos de morte. Enquanto pensávamos que íamos examinar criticamente etnografias de biossegurança no século XIX, eis-nos a pensar a necropolítica do século XXI. É essa a febre que trazemos a bordo hoje, é esse o desafio para o próximo ciclo de trabalhos.

\section{Referências}

ARNOLD, D. (ed.) Imperial medicine and indigenous societies. Oxford: Oxford University Press, 1988.

ARNOLD, D. Colonizing the body. Berkeley: University of California Press, 1993.

BAHADUR, G. Coolie woman: the odyssey of indenture. Durham: Duke University Press, 2014.

BALA, P. Imperialism and medicine in Bengal: a socio-historical perspective. New Delhi: Sage Publications, 1991.

BASTOS, C. Germ theories in a colonial setting: medical theories and military practices in late nineteenth century Goa, India. EASST Review, v. 17, n. 4, p. 9-12, 1998. 
BASTOS, C. Global responses to AIDS: science in emergency. Bloomington: Indiana University Press, 1999.

BASTOS, C. Doctors for the Empire: the Medical School of Goa and its narratives. Identities, v. 8, n. 4, p. 517-548, 2001.

BASTOS, C. Ciência, poder, acção: as respostas à sida. Lisboa: Imprensa de Ciências Sociais, 2002.

BASTOS, C. Um luso-tropicalismo às avessas: colonialismo científico, aclimação e pureza racial em Germano Correia. In: RIBEIRO, M. C.; FERREIRA, A. P. (org.) Fantasmas e fantasias imperiais no imaginário português contemporâneo. Porto: Campo das Letras, 2003. p. 227-253.

BASTOS, C. O ensino da medicina na Índia colonial portuguesa: fundação e primeiras décadas da Escola Médico-Cirúrgica de Nova Goa. História, Ciências, Saúde-Manguinhos, v. 11, n. 1, p. 11-39, 2004.

BASTOS, C. Race, medicine and the late Portuguese empire: the role of Goan colonial physicians. Journal of Romance Studies, v. 5, n. 1, p. 23-35, 2005.

BASTOS, C. Medicina, império e processos locais em Goa, século XIX. Análise Social, v. 42, n. 182, p. 99-122, 2007a.

BASTOS, C. Medical hybridisms and social boundaries: aspects of Portuguese colonialism in Africa and India in the nineteenth century. Journal of Southern African Studies, v. 33, n. 4, p. 767-782, 2007b.

BASTOS, C. Migrants, settlers and colonists: the biopolitics of displaced bodies. International Migration, v. 46, n. 5, p. 27-54, 2008.

BASTOS, C. Maria Índia, ou a fronteira da colonização: trabalho migração e política no planalto sul de Angola. Horizontes Antropológicos, Porto Alegre, ano 15, n. 31, p. 51-74, 2009.

BASTOS, C. Tracking global flows and still moving: the ethnography of responses to AIDS. In: MELHUUS, M.; MITCHELL, J. P.; WULFF, H. (ed.). Ethnographic practice in the present. Oxford: Bergham, 2010. p. 135-151.

BASTOS, C. Trânsitos atlânticos, pacíficos e terrestres - a pequena grande história de Maria Índia. In: AREND, S.; RIAL, C.; PEDRO, J. (org.). Diásporas, mobilidades e migrações. Florianópolis: Editora Mulheres, 2011a. p. 69-78.

BASTOS, C. (org.). Clínica, arte e sociedade: a sífilis no Hospital do Desterro e na saúde pública. Lisboa: Imprensa de Ciências Sociais, 2011b. 
BASTOS, C. From sulphur to perfume: spa and SPA at Monchique, Algarve. Anthropology and Medicine, v. 18, n. 1, p. 37-53, 2011c.

BASTOS, C. Banhos de princesas e de lázaros: termalismo e estratificação social. Anuário Antropológico, v. 36, n. 2, p. 107-126, $2011 d$.

BASTOS, C. Displayed wounds, encrypted messages: hyper-realism and imagination in medical moulages. Medical Anthropology, v. 36, n. 6, p. 533-550, 2017.

BASTOS, C. Portuguese in the cane: the racialization of labour in Hawaiian plantations. In: ABOIM, S.; GRANJO, P.; RAMOS, A. (ed.). Changing societies: legacies and challenges. Lisboa: Imprensa de Ciências Sociais, 2018a. v. 1, p. 65-96.

BASTOS, C. Migrants, inequalities and social research in the 1920s: the story of two Portuguese communities in New England. History and Anthropology, v. 29, n. 2, p. 163 183, $2018 \mathrm{~b}$.

BASTOS, C. Lusotropicalism debunked, again: race, racism, and racialism in three Portuguese-speaking societies. In: ANDERSON, W.; ROQUE, R.; SANTOS, R. V. (ed.). Luso-tropicalism and its discontents: the making and unmaking of racial exceptionalism. Oxford: Berghahn, 2019a. p. 243-264.

BASTOS, C. Açúcar, ananases e ilhéus portugueses no Hawaii. Etnográfica, v. 23, n. 3, p. 777-798, 2019b.

BASTOS, C.; DELICADO, A.; MATOS, A. P. Arte, clínica, ciência e património: uma colecção de moldagens de um antigo hospital de dermatologia e sífilis em Lisboa. Amazônia, v. 5, n. 2, p. 258-287, 2014.

BOLSTER, J. Black jacks: African American seaman in the age of sail. Cambridge: Harvard University Press, 1997.

BROWN, K. The pox: the life and near death of a very social disease. Thrupp: Sutton Publishing, 2006.

BROWN, K. Passage to the world: the emigrant experience, 1807-1940. Barnsley: Seaforth publishing, 2013.

CALDEIRA, S. Da Madeira para o Hawaii: a emigração e o contributo cultural madeirense. Funchal: CEHA, 2010.

CARRARA, S. Tributo a Vênus: a luta contra a sífilis no Brasil, da passagem do século aos anos 40. Rio de Janeiro: Editora Fiocruz, 1996.

CHRISTOPHER, E. Slave ship sailors and their captive cargo. Cambridge: Cambridge University Press, 2016. 
CORREIA, A. C. G. da S. Os eurafricanos de Angola: estudo antropológico. Lisboa: [s.n.], 1925. CORREIA, A. C. G. da S. Os luso-descendentes de Angola: contribuição para o seu estudo antropológico. In: MEMORIA do $3^{\circ}$ Congresso Colonial Nacional. Lisboa: Sociedade de Geografia: Tipografia Carmona, 1934. p. 867-917.

CORREIA, A. C. G. da S. India Portuguesa: prostituição e profilaxia anti-venérea: história, demografia, etnografia, higiene e profilaxia. Bastora: Tipografia Rangel, 1938.

CROSBY, A. The Columbian exchange. Westport: Greenwood, 1972.

CURTIN, P. Disease and empire. Cambridge: Cambridge University Press, 1998.

D'OLIVEIRA, J. B.; D'ORNELLAS, V.; CANARIO, L. Destination Sandwich Islands. Hawaiian Journal of History, n. 4, p. 3-52, 1970.

DELICADO, A.; BASTOS, C. O corpo medicalizado nos museus. In: CASCAIS, A. F. (org.). Olhares sobre a cultura visual da medicina em Portugal. Alfragide: UnyLeya: CECL, 2014. p. 38-66.

FIELDS, K.; FIELDS, B. Racecraft: the soul of inequality in American life. New York: Verso, 2012.

GESCHWENDER, J. A.; CARROLL-SEGUIN, R.; BRILL, H. The Portuguese and Haoles of Hawai'i: implications for the origin of ethnicity. American Sociological Review, v. 53, n. 4, p. 515-527, 1988.

HANNERZ, U. Transnational connections: culture, people, places. New York: Routledge, 1996.

HOCHMAN, G. A era do saneamento: as bases da política de saúde pública no Brasil. São Paulo: Hucitec, 1998.

LADWIG, P. et al. Fieldwork between folders: fragments, traces, and the ruins of colonial archives. Halle: Max Planck Institute for Social Anthropology, 2012.

LATOUR, B. Nous n'avons jamais été modernes: essai d’anthropologie symétrique. Paris: La Découverte, 1991.

LEVINE, P. Prostitution, race, and politics: policing venereal disease in the British Empire. New York: Routledge, 2003.

LIMA, N. T. Um sertão chamado Brasil: intelectuais e interpretações geográficas da identidade nacional. Rio de Janeiro: Revan, 1999.

MacLEOD, R.; LEWIS, M. (ed.). Disease, medicine and empire: perspectives on Western medicine and the experience of European expansion. London: Routledge, 1988. 
MADSEN, L. Report from the conference "Epidemics Entanglements: Exploring the interrelation between Cities and Infectious Disease," Frankfurt am Main, July 24-25, 2014. Curare, v. 37, n. 4, p. 269-273, 2014.

MANDERSON, L. Sickness and the state: health and illness in colonial Malaya, 18701940. New York: Cambridge University Press, 1996

MELLO, M. M. Madeirans and Creoles labourers: thinking through race and labour in post-emancipation British Guiana. 2019. Trabalho apresentado. International Conference "Labor, Sugar and Long Distance Migration". CEHA, Funchal, Madeira, 14-15 nov. 2019.

MENEZES, M. N. Scenes from the History of the Portuguese in Guyana. London: Victoria Printing Works, 1986.

MENEZES, M. N. The Portuguese of Guyana: a study in culture and conflict. Gujarat: Anand Press, 1992.

MIGUÉIS, J. R. The polyhedric mirror: tales of American life. Providence: Gavea-Brown, 2005.

MILLER, N. Crossing seas and labels: Hawaiian contracts, British passenger vessels and Portuguese labor migrants, 1878-1911. Portuguese Literary and Cultural Studies, Special Issue Ocean Crossings, no prelo.

MOORE, B. The social impact of Portuguese Immigration into British Guiana after emancipation. Boletín de Estudios Latinoamericanos y del Caribe, n. 19, p. 3-15, 1975.

MUSTAKEEM, S. M. Slavery at sea: terror, sex and sickness in the Middle Passage. Urbana: University of Illinois Press, 2016.

NAIPAUL, V. S. The Middle Passage: impressions of five colonial societies. London: Picador, 1996.

NEWITT, M. Emigration and the sea: an alternative history of Portugal. New York: Oxford University Press, 2015.

OLIM, G. A emigração portuguesa para o Havai entre 1878 e 1913: perspetiva da imprensa havaiana da época. Islenha, n. 63, p. 55-86, 2019.

PACKARD, R. White plague, black labor: the political economy of health and diseases in South Africa. Berkeley: University of California Press, 1989.

PEERTHUM, S. They came to Mauritian shores: the lifes-stories and the history of the indentured labourers in Mauritius (1862-1937). Port-Louis: Aapravasi Ghat Trust Fund, 2017 
QUINTELA, M. M. Curar e recrear em águas termais: um diálogo etnográfico entre Portugal (Termas de São Pedro do Sul e Termas da Sulfúrea) e Brasil (Caldas da Imperatriz). Anuário Antropológico 2010/2, p. 169-194, 2011.

QUINTELA, M. M. Seeking 'energy' vs pain relief in spas in Brasil (Caldas da Imperatriz) and Portugal (Termas da Sulfúrea). Anthropology and Medicine, v. 18, n. 1, p. 23-25, 2011b.

REDIKER, M. Between the devil and the deep blue sea. New York: Cambridge University Press, 1989.

REDIKER, M. The slave ship: a human history. London: John Murray, 2007.

RODNEY, W. A history of the Guyanese working people, 1881-1905. Baltimore: Johns Hopkins University Press, 1981.

ROSENBERG, C. The cholera years: the United States in 1832, 1849, and 1866. Chicago: The University of Chicago Press, 1988.

SARAIVA, L. O renascer de Vénus: prostituição, trabalho e saúde em tempos de Sida. Lisboa: Imprensa de Ciências Sociais, 2009.

SCHEPER-HUGHES, N. Death without weeping: the violence of everyday life in Brazil. Berkeley: University of California Press, 1992.

SEGATA, J. O mosquito da indiferença. Estudos Feministas, v. 25, n. 2, p. 975-978, 2017. SPRANGER, A. I. Guiana Inglesa. Aprender Madeira, 13 dez. 2017a. Disponível em: http://aprenderamadeira.net/guiana-inglesa/. Acesso em: 5 out. 2019.

SPRANGER, A. I. Havai, emigração para o. Aprender Madeira, 30 dez. 2017b. Disponível em: http://aprenderamadeira.net/havai-emigracao-para-o/. Acesso em: 5 out. 2019.

STEELE, P. R. The girl immigrant. Casa Grande: Plumeria Press, 2013.

STOLER, A. L. Along the archival grain: epistemic anxieties and colonial common sense. Princeton: Princeton University Press, 2010.

THOMPSON, E. T. Plantation societies, race relations and the South: the regimentation of populations. Durham: Duke University Press, 1975.

THOMPSON, E. T. The plantation. Columbia: The University of South Carolina Press, 2010.

Recebido: 20/10/2019 Aceito: 21/11/2019 | Received:10/20/2019 Accepted:11/21/2019 